\title{
Ray Caesar's Digital Illustrations
}

\author{
Zhicheng Wei \\ School of Art and Architecture \\ Hefei University of Technology \\ Hefei, China 230001
}

\begin{abstract}
Ray Caesar is an important contemporary artist of digital illustrations, who uses digital illustrations to describe Rococo dreamland in his heart. In his works, the picture is pretty colorful with vivid details, which has a quality of classical oil paintings. He contributes to digging people's inner world and subconsciousness, so his works is filled with whim and mysterious metaphor. His creation also brings a new breath for digital illustrations.
\end{abstract}

Keywords-digital illustrations; subconsciousness; Rococo style

\section{INTRODUCTION}

Digital illustrations is a new art pattern which is surged with the popularization of computer and the development of software technology. As a new tool to produce pictures, digital illustration has its advantages such as replicability and easy to modify. It makes digital art widely adapted to various commercial graphics production. Today, we can find digital illustrations in kinds of films, games and animation. Artists embarked on traditional creation begin to create by digital illustrations. Due to its speciality, digital works is always refreshing on visual effect. However, its visual rule has much relation with traditional drawing and sculpture. Creating with digital illustrations also becomes a trend, while the works of Ray Caesar is very outstanding among them.

\section{RAY CAESAR'S ART LIFE STORIES AND CREATED PATTERN}

Ray Caesar, born in London in 1958, immigrated to Toronto, Canada in 1976. From 1976 to 1980, he studied in OCAD University and then settled in Canada. He worked in the arts and photography department in a Children's hospital to draw medical illustration, which lasted about 17 years. To an amateur artist, 17 years is very long for accumulation. His main task in the hospital was to record some visual materials of Children who suffered maltreatment and their recovery after operation. He once spent much time on medical illustration and scientific mapping. These experiences improved his drawing skills and shape ability as well as his attention on details.

Because of his unique experiences, Ray Caesar paid more attention to psychological trauma and psychological problems than others, which exactly gives his creation distinct view and theme. In 2001, something happened in his family hurt him badly in heart, it set off Ray Caesar's creation desire which has been buried in his heart for a long time. He resigned from the hospital and spent 3 years on writing the novel named the Emissary about subconsciousness. At the same time, he tried to create by digital illustrations. There are many soft-wares that can make digital pictures. In general, they can be divided into two kinds: two-dimension and three-dimension software. Ray Caesar selected three dimension software Maya as the main tool to make Static frame illustrations. Years of inner feelings and artistic ideas were expressed in this 3D virtual world. He found an artistic career that fitted him very well. At that time, he was more than 40 years old, so art became the only spiritual ballast for him. From 2003, he constantly publishes his digital illustration pictures and produces some works with classical surrealistic style.

\section{ARTISTIC CHARACTERISTICS OF RAY CAESAR' S WORKS}

In Ray Caesar's works, there are full-tasting loneliness and erotic feelings, which forms his unique aesthetic style. There is an elusive mystery and a fantastic color in his works and people in his works are always live in a dreamlike world. He worked in a children hospital for a long time, so the pubertal maiden is also one of the core themes. The protagonists in his works are usually sub-debutantes, who are vulnerable and decadent, indifferent and aggradevoled. These girls place themselves in lavish Rococo palaces or go through the quiet forest in mysterious castle, or stand in the bleak white sand beach. They are reserved or indulgent, or addicted to narcissistic self-talk, or caught in the lusts which cannot extricate, giving an infinite imagination to readers.

Ray Caesar's illustrations are narrative. Like many surrealist artists, most of the themes he expresses are from the stream of consciousness. In his works, he always shows the loneliness of young girls, Split personality, quiet and mysterious date, girls' shy but longing dirty dreams, as well as kinds of Absurd bizarre lust and subconscious. He uses strong metaphor in his works, while what he values most is that about sex. In the picture Family hypocrisy, at the corner of a Rococo building, a girl in orchid silk yarn skirt, with small high heels, back to the viewer, sat on a dressing stool with red carpet, as if thinking of some things. But there was a pink tail behind her and provoked her dress, revealing her hips. The color tone of whole picture is plain and downy, and cool picture conveys a touch of erotic meanings.

While in another works the light of early morning, the expression about sex is even stronger. It is on a fresh morning, the girl's boudoir was bathed in the morning light. Soft bright 
lake blue interior decoration and gold wood furniture formed perfectly. A girl with a mask and goggles lied on the couch with hands on the breasts. She seemed to in and out of sleep, lightly closed eyes moving lips, as if still immersed in the dirty dream last night, she held up legs to do a deeply moved posture, giving the infinite reverie.

In terms of shape, Ray Caesar's works was affected by Rococo painters Watteau, Jean Antoine and Bouchez. The protagonists in his pictures are light in body, exquisite and delicate. Their skins are smooth and shiny, as if they can be broken by a slight touch. They are innocent and charming, but the eyes are always showing a trace of uneasy or rebellious expression. The environment and props in the picture also have the characteristics of Rococo art and full of the curve of shells composition and delicate decoration. The hairstyle of the characters was the popular style of the French seventeenth century, and the popularity of this hairstyle lasted until the last period of the reign of King Louis XIV. The costumes of the characters were mostly lacquered bell-shaped skirts, giving a strong sense of form and grace. He recreated a surrealist Rococo dream with countless patterns and details, which also comforted the empty and tired mind of the modern people. Caesar uses Maya to make a new interpretation of the Rococo art, which can be said that this is a new way of contemporary art. That is, using new materials and media to re-create the traditional art. This is very worthy of contemporary artists to learn from. There are a lot of very good and classic traditional art forms in China, such as various folk art and craft, so how to use the new technology in the era of new media to interpret the tradition is still an anticipated theme. In recent years, a lot of China's digital artists are trying to use digital art to expand and play traditional art, and Ray Caesar's exploration is worthy of our careful analysis.

Ray Caesar's work also has its own characteristics in color. He likes to use soft colors, so yellow and blue are main colors in his works. They match light rose red on the body, giving the screen a fantastic realm, and also forms Ray $\bullet$ Caesar's soft and beautiful visual characteristics. At the same time, he also likes to use some intense color to strengthen emotions of the pictures. He uses the red and pure black to express a strong sense of drama. Red is a symbol of bloody, violent and sexual desire in his works, while black implies danger, mystery, and intact loneliness. The girl in the picture sometimes dressed in gorgeous red evening dress, with a lusty sexy red lips. She was being tortured by the pain of her sexual desire, signing a moan difficult to hide. They sometimes sank into the boundless loneliness, exposed to the dark black, as if they got to the end of the cold world. Black brings his works more mysterious temperament and metal-like solemn feelings.

\section{MAKING Methods OF RAY CAESAR's 3D ILLUSTRATIONS}

Ray Caesar's illustrations are made by three-dimensional software, which involves some specific three-dimensional production skills. Creating images by three-dimensional software is not simple, it has many processes. The first step is to make the model according to sketches. Ray Caesar pursues in-depth and exquisite shape, so in the modeling stage he takes the trouble to shape in details. Everything in this picture is built with polygon topology, which is equivalent to a sculpture process. Caesar pays uncompromising attention on the works of furniture, carving, the shape of objects like watches and clocks as well as clothing accessories, so people can appreciate every part of the works deeply. He also changes the image of the characters, puts the physical modeling of some animals into the human body, or exaggerates some of the characters. In the low tide and black angel, he changes the character's feet below the skirt into the octopus tentacles, outward spread, giving a sense of absurdity. Sometimes he gives people two shrimp-like arms, such as characters in messenger, making the original quiet picture with a trace of uneasy atmosphere. In addition to modeling, to make three-dimensional illustrations, we also need suitable map and materials to match the shape. Ray Caesar is very concerned about illustrating and collecting the model above the map because fabric, wood, marble and metal have different texture and color relationship. He once said: "Some people collect stamps, and I collect the surface material." It can be said that his work is the perfect combination of silk, marble as well as their skin texture.

\section{CONCLUSION}

Ray Caesar's art is subtle and restrained, and his works vaguely shows danger, injury and uneasiness, and he carefully controls the expression of these emotions, trying to create a world of adult fairy tales full of spirituality and fantasy. His talent is accumulated and late-blooming, and today there are many artists inspired by his works. Although he uses digital technology to illustrate works, he does not produce some popular commercial digital illustrations as the flow, but from his personal feelings and life experience and sank in the depths of art history to find inspiration. This kind of traditional mining also brings a new concept to digital art. In recent years, his digital illustrations continue to be shown in the major galleries and his fame is also growing, and recognized by the contemporary art world. The success of every artist has its subjective and objective reasons, and cannot be copied, while Ray Caesar's combination and grafting of traditional Rococo art and three-dimensional digital art is worth learning. China has a long history and splendid traditional culture, so how to make traditional art into the modern context to express of modern people's thoughts and feelings is also an important task faced by Chinese artists.

\section{REFERENCES}

[1] Zhang Hui.Transcending the Real World - On the Application of Surreal Elements in Digital Illustrations[J].popular literature and arts.2010.22

[2] Wang Shouzhi..American illustrated history [M].Beijing:China Youth Publishing House,2002 